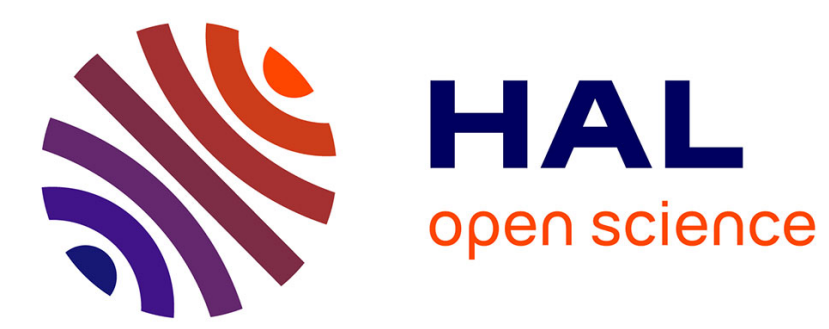

\title{
Cavalcanti, Bartolomeo
}

Véronique Montagne

\section{- To cite this version:}

Véronique Montagne. Cavalcanti, Bartolomeo. 2017. hal-01477237

\section{HAL Id: hal-01477237 \\ https://hal.science/hal-01477237}

Preprint submitted on 9 Jun 2017

HAL is a multi-disciplinary open access archive for the deposit and dissemination of scientific research documents, whether they are published or not. The documents may come from teaching and research institutions in France or abroad, or from public or private research centers.
L'archive ouverte pluridisciplinaire HAL, est destinée au dépôt et à la diffusion de documents scientifiques de niveau recherche, publiés ou non, émanant des établissements d'enseignement et de recherche français ou étrangers, des laboratoires publics ou privés. 


\title{
Cavalcanti, Bartolomeo
}

Born: Florence, 1503

Died: Padoue, 1562

Véronique Montagne

montagne@unice.fr

Université Nice Sophia Antipolis, CNRS, BCL, UMR 732

98 Bd Edouard Herriot

BP 3209 - 06204 Nice Cedex France

http://www.unice.fr/bcl

\begin{abstract}
:
Bartolomeo Cavalcanti est un noble florentin, diplomate, traducteur et orateur et adversaire des Médicis.
\end{abstract}

\section{Biography :}

Bartolomeo Cavalcanti prend part à la défense de Florence pendant le siège de 1530 durant lequel une armée du Saint-Empire et d'Espagne encercle la ville, renverse la République florentine et promeut Alexandre de Médicis duc de Toscane. Après l'assassinat du duc, en 1537, il s'exile volontairement de Florence et entre au service d'Hercule II d'Este. En 1548, il est à Rome, au service de Paul III (Alexandre Farnèse), puis d'Ottavio Farnèse, petit-fils de Paul III. Sous les murs de Sienne, il combat François $1^{\text {er }}$ de Médicis, petit-fils et successeur de Cosme ${ }^{\text {er }}$.

\section{Works :}

Bartolomeo Cavalcanti est notamment l'auteur de La retorica divisa in sette libri con le postille di Pio Portinatio, parue à Venise chez Giolito de Ferrari en 1558. À partir de l'année suivante, l'ouvrage est publié sous le titre La retorica di m. Bartolomeo Cavalcanti, gentil'huomo fiorentino. [...] Con le postille di m. Pio Portinaio giureconsulto, che dimostrano sommariamente tutto quello, che vi si tratta. Le texte connait un certain succès : à côté de cette édition de Giolito de Ferrari, parue en 1559, on peut signaler les éditions de 1559 (Pise : B. Cesano), 1560 (Venise : G. de Ferrari), 1564 (Pesaro : B. Cesano), 1569 (Venise : B. Robini), 1578 (Venise : C. Franceschini) ou 1585 (Venise : Zoppini fratelli). La retorica est une rhétorique complète, comprenant des considérations sur l'elocutio, l'inventio, la dispositio, l'elocutio et la prononciation. Sa rhétorique intègre les apports d'Aristote, mais aussi de Cicéron, Quintilien, Hermogène de Tarse, Démétrius de Phalère, Themistius ou Georges de Trébizonde.

Cavalcanti est également traducteur de Polybe, auteur de discours faits à la milice florentine (1529), d'un jugement sur la tragédie Canace et Macareo de Sperone Speroni (1550) ou encore d'une réflexion sur les types de république.

\section{References :}

Cavalcanti, Bartolomeo. 1529. Oratione di Bartholomeo Cavalcanti fatta alla militare ordinanza fiorentina, il di III di febraio, MDXXV IIII. Firenze : haer. Filippo I Giunta. 
Cavalcanci, Bartolomeo. 1550. Giuditio sopra la tragedia di Canace e Macareo (di S. Speroni), con molte utili considerationi circa l'arte tragica, et di altri poemi, con la tragedia appresso. Lucca : Busdrago.

Cavalcanti, Bartolomeo. 1559. La retorica di m. Bartolomeo Cavalcanti, gentil'huomo fiorentino. Divisa in sette libri dove si contiene tutto quello, che appartiene all'arte oratoria. Con le postille di m. Pio Portinaio giureconsulto, che dimostrano sommariamente tutto quello, che vi si tratta. Et con la tavola de i capi principali contenuti nella presente opera. Venise : G. de Ferrari.

Cavalcanti, Bartolomeo. 1570. Trattato primo (-quinto decimo) del S. Bartolomeo Cavalcanti sopra le spetie delle republiche (con tre lettere del Sig. Bartholomeo Cavalcanti sopra la riforma d'una republica fatta da lui). Venetia : J. Sansovino.

Cavalcanti, Bartolomeo. 1571. Trattati overo discorsi di m. Bartolomeo Cavalcanti sopra gli ottimi reggimenti delle republiche antiche et moderne. Con un discorso di $m$. Sebastiano Erizo gentil'buomo vinitiano de governi civili. Ne' quali con molta dottrina si mostra quanto siano utili i governi publici, et quanto necessari i privati et particolari per conservation del genere bumano, dichiarandosi tutte le qualità degli stati. Venezia : G.

Sansovino.

Cavalcanti, Bartolomeo. 1967. Lettere edite e inedite, a cura di Christina Roaf. Bologna : Commissione per i testi di lingua.

Cavalcanti, Bartolomeo. 2007. Trattati o vero discorsi sopra gli ottimi reggimenti delle republiche antiche e moderne, a cura di Enrica Fabbri. Milano : F. Angeli.

Montagne, Véronique. 2009. Du bon usage de l'ambiguïté à la Renaissance : le traitement du discours érotique dans La retorica de Bartolomeo Cavalcanti (1558). Réforme, Humanisme, Renaissance, volume 69, $\mathrm{n}^{\circ} 1: 105-123$.

Roaf, Christina. 1958. L'elocuzione nella Retorica di Bartolomeo Cavalcanti. La critica stilistica e il letterario, atti del secondo congresso internazionale di studi italiani. Firenze : Le Monnier : 316-319. 